\title{
Non-governmental organizations and KM: A human centric approach
}

\author{
Iftikhar Hussain $^{\mathrm{a}^{*}}$, Waheed Akhtar ${ }^{\mathrm{b}}$ and Shahid Hussain ${ }^{\mathrm{b}}$
}

${ }^{a}$ Faculty of Administrative Sciences, Kotli (FASK), University of Azad Jammu \& Kashmir, Pakistan \& PhD Scholar School of Management, Shanghai University, Shanghai 200444, PR China

${ }^{b}$ MPhil Scholar at Faculty of Administrative Sciences, Azad Jammu \& Kashmir University, Pakistan

\begin{tabular}{|c|c|}
\hline ART I C L E I NFO & ABSTRACT \\
\hline $\begin{array}{l}\text { Article history: } \\
\text { Received August } 19,2011 \\
\text { Received in Revised form } \\
\text { November, } 11,2011 \\
\text { Accepted } 12 \text { November } 2011 \\
\text { Available online } \\
16 \text { November } 2011 \\
\text { Keywords: } \\
\text { NGO } \\
\text { HRs } \\
\text { KM } \\
\text { Individuals } \\
\text { Organization }\end{array}$ & $\begin{array}{l}\text { Non-governmental organizations need to manage their knowledge similarly to for-profit } \\
\text { organizations. Although for effective KM a technology, people, task, and structure - integrated } \\
\text { approach is required. However, there is a strong imperative to develop people capabilities } \\
\text { within Non-governmental organizations in order to meet the challenges of economic, social and } \\
\text { environmental development. Therefore, in this study we have particularly examined the impact } \\
\text { of human resources on KM effectiveness in the nonprofit industry. The study deals with three } \\
\text { major research questions: (1) Does the level of human resources' knowledge have a positive } \\
\text { influence on a Non-governmental organization's KM capabilities? (2) Does a Non- } \\
\text { governmental organization's KM capability positively influence its knowledge processing } \\
\text { capability? (3) Does a Non-governmental organization's knowledge processing capability } \\
\text { positively influence its performance? Further, the study aims to investigate human resource } \\
\text { management related issues in KM implementation in nonprofit industry, and attempts to } \\
\text { provide appropriate solutions. Finally, the study proposed KM model for nonprofit industry. }\end{array}$ \\
\hline
\end{tabular}

\section{Introduction}

The term, "non-governmental organization" or NGO, came into use in 1945 (Mostashari, 2005). KM is a vital resource of efficiency improvement and service expansion in non-governmental organizations (NGOs). As Caldwell (2004) identified that non-profits are making significant investments in knowledge management (KM) for the long term development of KM.

In present competitive environment, knowledge is a critical factor for business activities supporting organizational strategies (Kerschberg, 2001). The success of an organization depends on effective management of its' internal and external knowledge (Egbu, 1999; Switzer, 2008). Knowledge must

\footnotetext{
* Corresponding author. Tel: +989183655625

E-mail addresses: iftikhar_raja@live.com (I. Hussain)

C) 2012 Growing Science Ltd. All rights reserved. 
circulate among individual knowledge workers, who should learn from each other to keep themselves updated, and productive (Giuseppe et al., 2010).

Recently, KM has become an emerging trend in large as well as small firms. The capability to effectively manage knowledge occupied by a company's employee is a great challenge specifically to NGOs. In business enterprises, the concept of KM is more extensively practiced. The nonprofit industry, however, have not caught the essence of KM practices. There is lack of research on this critical issue, only few studies have been conducted on this issue. However, the present study deals with KM development in non-profit industry and its importance and significance for non-profit industry.

Several studies described knowledge as an important source of competitive advantage (Alavi \& Leidner, 2001; Grant, 1996; Nah et al., 2005). Considering the value of KM, many organizations have started making substantial investments in information technology in implementing KM systems (Grover \& Davenport, 2001; Kwan \& Balasubramanian, 2003). However, since knowledge in a NGO is the result of different social interactions between individuals and groups, effective human resource policies are essential for better KM. Human capital is a vital source of knowledge in nonprofit industry; therefore, this study examined and proposed a human centric approach to KM in NGOs.

Nonprofit industry is a diverse nature industry, where in some projects few organizations work in joint-ventures and help each other at various stages during the project lifecycle. Such projects have multi-stakeholders, which may or may not continue to work together once the project is finished. All these stakeholders communicate a large amount of information and knowledge. Improving KM capabilities of the industry can result better performance of project at hand as well as in future. Along with this pressure is also mounting from clients who demand better services in shorter duration and using fewer resources. Therefore, in this study KM has been viewed as a strategy to develop nonprofit industry and improve their efficiency.

Managing existing knowledge is vital to obtain or develop new knowledge. Creating new knowledge enables organizations to develop new products and add value in existing products through innovation (Smith et al., 2005). However for effective management of existing knowledge requires improved knowledge processing capabilities. In order to improve the knowledge processing capabilities, the NGOs' need to improve KM capabilities of their human resources (HRs). The study deals with three major research questions: (1) Does the level of HRs knowledge have a positive influence on a NGO's KM capabilities? (2) Does a NGO's KM capability positively influence its knowledge process capability? (3) Does a NGO's knowledge processing capability positively influence its performance?

Knowledge has been considered as a key asset and increasingly managed in private sector in order to maintain a competitive advantage (Davenport \& De Long, 1998). Whether the NGOs' should initiate KM implementation or how NGOs' should put KM initiatives into practice are still unclear. The paper attempts to analyze the ongoing research efforts and work related to KM in the nonprofit industry. It critically analyzes and highlights the problems NGOs face in implementing a KM approach. Specifically the study aims to investigate HR related issues in KM implementation, and attempts to provide appropriate solutions. Subsequent to this introduction, the paper presents relevant literature about knowledge, KM, and KM and HRs relationship.

This is followed by a review of KM in the nonprofit industry and other issues arising in $\mathrm{KM}$ implementation in nonprofit industry. Section 4 introduces the proposed KM-Model for NGOs. The final section draws out the contribution of the paper, provides conclusive remarks and directions for the future. 


\section{Literature review}

\subsection{Knowledge}

In today's knowledge economy, firm's performance heavily depends on the efficient and effective use of knowledge (Grant, 1996). In literature knowledge has been defined in several ways. Davenport and Prusak (1998) define knowledge as a fluid mix of framed experience, values, contextual information, and expert insight that provides a framework for evaluating and incorporating new experiences and information. The distinction between knowledge and information is still in debate. Nonaka (1994) considers information to be just "a flow of messages" whereas knowledge is based on information and justified by one's belief. Alavi and Leidner (2001) apply "knowledge" to suggest that there is value and uniqueness in examining KMS compared to the traditional information systems. Bartol and Srivastava (2002) use the terms knowledge and information interchangeably, and considers not much difference in practical applications.

Knowledge can be typically categorized in three different classes: tacit, explicit and implicit knowledge (Barth, 2004). Explicit knowledge is knowledge that can be articulated, codified, easily transferred between persons, digitized in documents and communicated in natural language (Grant \& Shahsavarani, 2006). In contrast to explicit knowledge, tacit knowledge is difficult to express, formalize or share. An individual interprets tacit knowledge as intuition, rather than as facts he is conscious of having and can explain to others. Tacit knowledge can be described as "knowing how" while explicit knowledge means "knowing what". Implicit knowledge is knowledge that is embedded within cultures, relationships and communities (Barth, 2004).

Tacit knowledge is the most important source in growth and development of businesses, as it is a source of innovation and sustainable competitive advantage (Lubit, 2001). Tacit knowledge is important as most of the knowledge in the world is in tacit form; almost 80 percent of all knowledge is in tacit form (Dalkir, 2005). The knowledge in non-profit industry is mostly comprised tacit form. The growth of tacit knowledge is more individual or personal capabilities' dependent, which is the main consideration of present study.

\subsection{Knowledge management}

$\mathrm{KM}$ is quite common in business organizations, but for non-governmental organizations, it is still a new concept (Mclnerney, 2002). KM is regarded as a strategic and value-added endeavor for enhancing an organization's effectiveness in the changing social and business environment (Gray \& Meister, 2006; Sher \& Lee, 2004 ). KM has been defined in several ways. We have examined some of them here for better understanding of what KM is. Rumizen (2000) described KM as the systematic processes by which an organization identifies, creates, captures, acquires, shares and leverages knowledge. Laurie (1997) defines KM as the creation, acquisition, sharing, and utilization of knowledge for the promotion of organizational performance. In the words of Kinney (1998) "KM is a process by which an organization creates, captures, acquires, and uses knowledge to support and improve the performance of the organization." Along with effectively managing knowledge, KM also persuades individuals and organizations to utilize knowledge successfully.

KM has become essential in today's economy, as knowledge today is regarded as main factor for production in all types of organizations. KM literature contains a range of thoughts that can be broadly classified into three main themes. The techno-centric theme looks at developing technology to improve knowledge creation and transfer (Johannessen et al., 2001). The organizational theme finds out ways to improve organization design to support knowledge processes (Davenport et al., 1998) while the ecological theme explores ways to better interact people, their identities and the 
environment (Kimble \& Bourdon, 2008). The resourcefulness of KM and its emphasis on developing knowledge for organizational improvements makes it inevitable for NGO sector (Vasconcelos et al., 2005).

\subsection{Knowledge management and human resources}

$\mathrm{KM}$ is acknowledged as a people-centric system rather than an organizational-centric system (Buckman, 2005). There are three key elements of KM success, i.e. people, processes and technology. People are the most vital element, because managing knowledge successfully depends upon people's capabilities to create, share and use knowledge.

$\mathrm{KM}$ is a broad field and many $\mathrm{KM}$ approaches are employed. Literature identifies several approaches to KM, and ways to implement them (Alavi \& Leidner, 2001; Earl, 2001). Schultze (1999) categorize knowledge into two approaches; objectivist and subjectivist. The objectivist approach views knowledge as objects to be discovered (Hedlund, 1994). Whereas, a subjectivist approach implies that knowledge is concentrated in and linked to human experience and the social practice of knowing (Brown \& Duguid, 1998).

Many studies recognized that HRM concerns, like training and development, career development, pay and reward, and a supportive organizational culture are vital for managing knowledge within firms, as knowledge dependents on people (Carter \& Scarbrough, 2001; Currie \& Kerrin, 2003; Hunter et al., 2002). However, at present it is not clear to many NGOs, how developing HR capabilities could support a commitment to long-term development and better performance. More knowledge relevant to these areas is required to cater these KM-HR needs in a better way. This is generally important when several stakeholders are involved. Developing employees and management capabilities is vital within NGOs in order to work effectively to promote economic, societal and environmental development. Hence developing a strong tie between HRM and KM is essential in this area.

The human capital working in NGOs, range from IT professionals, to accountants, marketers, and management professionals. Emphasizing knowledge work and knowledge workers in NGOs should be effective having such divergent professionals. Management of the knowledge resource in NGOs and developing collaboration between these professional can leverage and share knowledge. This creation of new knowledge and sharing of knowledge can be a source of innovation and better performance. The growing affiliation between KM and HRM is undeniable.

A valuable KM system is built upon the knowledge of the HRs within an NGO. Therefore, upgrading employees' knowledge and skills is vital for organizations (Bhatt, 2001). HRs should have the abilities to employ knowledge within the system in accomplishing everyday activities. Therefore, HR is considered as the building block of KM development. Hence, in order to improve KM capacity; NGOs need to develop strategies to build up abilities of HRs of the organization.

Hwang (2003) recommends mentoring as an effective HR strategy to improve employees' knowledge abilities and enhance organizational performance. Studies stressed the need of training to improve employees' capabilities to manage knowledge (Ikhsan \& Rowland, 2004; Zaharias et al., 2001). Stewart (1994) described training in concerned field as the most efficient and effective way to attain knowledge and capture human wisdom. Therefore, improving employees' knowledge abilities through training and other HR practices will enable employees' skills to create, gain, share and use knowledge. 


\section{HR related KM issues for NGOs}

The need for knowledge workers and KM is increasing rapidly as NGOs are gradually more involved in services rather than goods. In order to get better organizational performance, knowledge of employees must be put to use: it must be incorporated into organizational activities and shared with others. NGOs need to develop a KM system and organizational culture that values and rewards the transferring of tacit knowledge to explicit knowledge. Supportive KM structure and culture both can promote sharing of knowledge between employees. The KM-HRM approaches like training, communities of practice, and mentor programs can improve such knowledge sharing.

The changing knowledge economy observed many problems, both technological and organizational. The NGO sector also needs to transform HRM to counter to changing requirements of the knowledge economy. The functions of HRM need to expand, to managing organizational capabilities, managing relationships and managing learning and knowledge (Lengnick-Hall \& Lengnick-Hall, 2003; SaintOnge, 2001). The HRM practices should also change their focus to encourage environments conducive to knowledge creation and promotion within NGOs.

In most of the cases NGOs often initiate operations without deep background knowledge of the problem and without capable HRs. In the NGOs, most of the employees deal with diverse kind of people. KM capabilities help them equip themselves with skillful techniques. Various experienced employees could act as a mentor to fresh HR. However, experienced staff retirements and high employee' turnover due to job security, salary and government vacancy hurts NGOs performance. At the time these HRs leave, they carry with them the valuable knowledge they possess. It directly affects the quality of services and organizational performance in NGOs.

Social problems are ever-increasing and becoming complex in nature. Managing such complicated problems is becoming a real challenge for NGOs, which means the need for knowledge workers has been increasing. Some of these problems are required to deal on urgent basis involving someone's life. To tackle with such problems in the shortest time would definitely require lot of KM abilities in HRs of such organizations. Studies also concentrated that HR departments should bring some modifications in existing HR system to effectively link human capital management and KM within organizations (Fitz-enz in Chatzkel, 2002; Saint-Onge, 2001).

Each individual and each organization should, must and could be an active development actor and agent if only could have the proper knowledge capital (understood as social, symbolic and, therefore, economic capital) to make a difference. Lack of human resource knowledge capabilities that could cut across NGOs competence and competition but also that could bridge NGOs, donors and beneficiaries in not a rational approach.

\section{KM-Model for NGOs}

Although the role of each NGO is to encourage KM processes within its own organization through the implementation of HR capabilities development programs, it is the human resource department's role to enhance KM capabilities of employees. Some recent studies concluded that HRM issues, such as recruitment and selection, education and development, performance management, pay and reward, as well as the creation of a learning culture are vital for managing knowledge within organizations (Currie \& Kerrin, 2003; Hunter et al., 2002). However, effective KM requires certain knowledge capabilities as indicated in the KM model presented. The proposed KM-model is based upon research questions raised in this study. 
Schuler and Jackson (2003) described three competitive advantage strategies from Porter's competitive advantage, 1) innovative strategy, (2) quality enhancement strategy, (3) cost reduction strategy. Schuler and Jackson (2003) also pointed out that the three strategies require people with different knowledge, abilities and technical skills, or role behaviours. However, these three strategies can be successfully implemented only by effective management of employees' knowledge and through effective implementation of KM processes. KM processes effectiveness and better performance largely depends upon employees and organizational KM capabilities. Therefore, enhancing HRs knowledge capabilities through human resource policies and practices is prerequisite for NGOs better performance and success.

The KM-model proposed in this study present a KM approach for NGOs, which views knowledge as the key asset of a NGO and systematically develops activities to manage it efficiently. The main objectives of KM are to promote knowledge creation, knowledge acquisition, knowledge sharing and knowledge utilization to improve knowledge processing abilities of a NGO, which ultimately can improve NGO performance. However to achieve these objectives NGOs need to develop certain KM capabilities, divided in two groups in the model, i.e. individual KM capabilities and organizational KM capabilities. These KM capabilities can be developed through effective human resource strategies like recruitment and selection, training and development and rewards systems. Recruitment and selection of individuals with equally right skills and right behaviour is vital for improving knowledge processing capabilities of an organization (Scarbrough, 2003).

HR Knowledge Capabilities

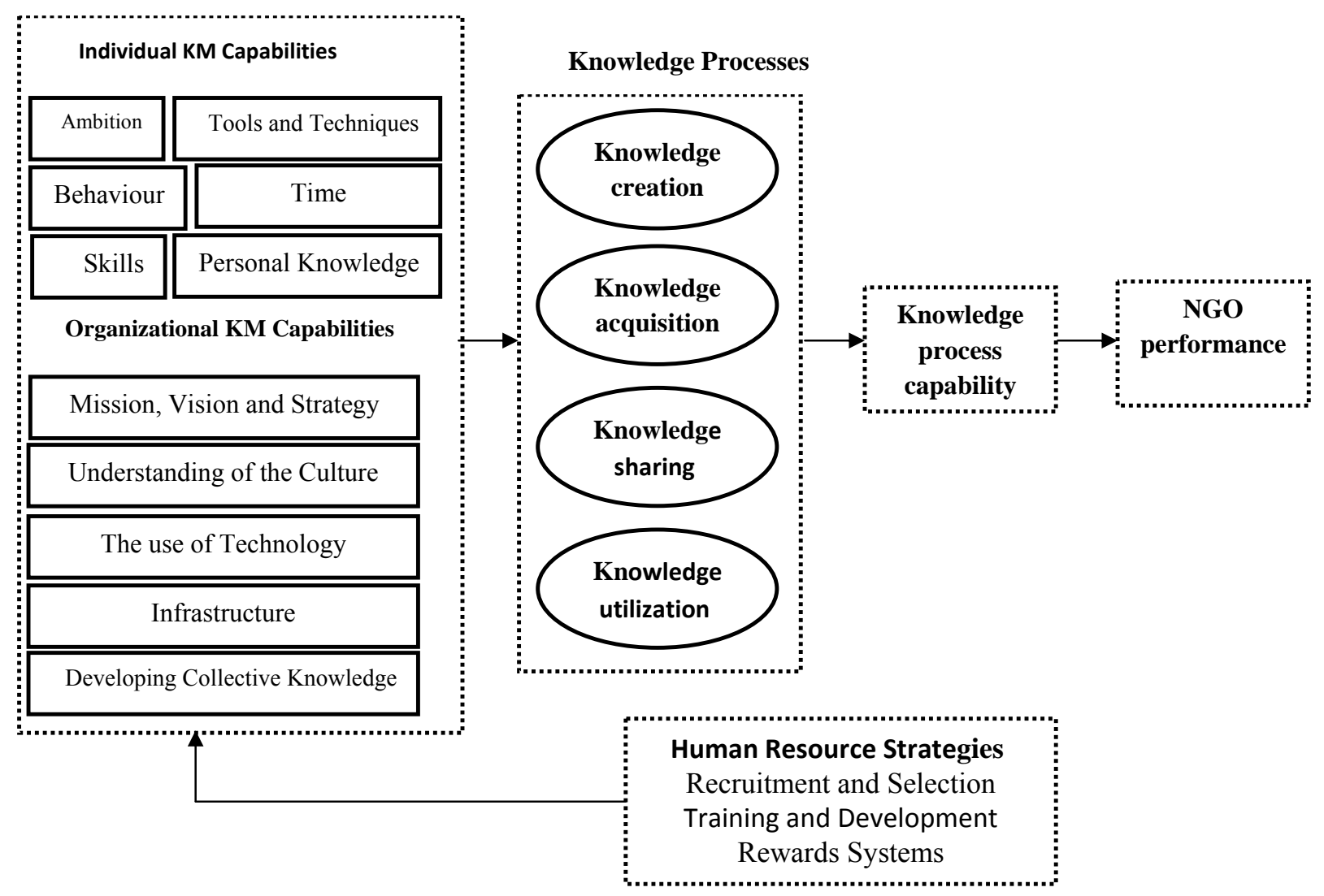

Fig. 1. KM-Model for NGOs 
NGOs' knowledge and expertise requirements are growing to become more innovative and competitive. NGOs need to change their conventional selection approaches and required to bring in more knowledge workers. The HR department through recruitment and selection process should ensure a fit between individuals and organizational knowledge culture (Swart \& Nicholas, 2003). This will also improve organizational knowledge processing capability and performance. Continuous professional development of employees in an organization is vital for their own development as well as organization's growth. Developing and leveraging employees' knowledge through training and development is critical (Robertson \& Hammesley, 2000).

HR-KM strategies in non-profit sector require that organizations hire different kinds of people and train them effectively. NGOs' which are more innovative hire more qualified graduates and train them in a more sophisticated way, to use their analytical and creative skills. NGOs' which are less innovative and needs to implement routine programs tend to hire undergraduates and train them in groups to be effective implementers.

Horwitz et al. (2003) emphasized the importance of rewards in knowledge acquisition, sharing and development. According to Evans (2003) performance management needs to consider the different ways in which individuals contribute knowledge and then link them to rewards. (1)What knowledge has the individual brought into the organisation? (2) How has the individual applied their knowledge to help others to develop? (3) How frequently has the individual re-used existing knowledge and what has been the outcome? (4) Has the individual actively developed his/her own knowledge and skills? How well has the individual applied his/her learning?

In views of Zárraga and Bonache (2003) those who produce are paid more rewards than those who share, therefore reward system needs to be modified. In knowledge society knowledge sharing is rather more important than solely producing. As collective knowledge that is very critical for any organization can be developed only through knowledge sharing. Finally as indicated in figure-1, the alignment of individual and organizational capabilities with KM processes is necessary to ensure better performance of KM systems in NGOs. The three HRM policies indicated in the model, (1) recruitment and selection, (2) training and development, and (3) rewards systems can play a critical role in this alignment.

\section{Conclusions}

This study has concentrated on how HR practices can enhance knowledge processing capabilities of NGOs and improve their performance. Strategies like selection and recruitment processes, training and development and reward systems are considered significant. KM-model signifies some key relationships between HRM and KM. the study concludes that HR strategies do not operate alone, therefore need to be carefully coordinated, specifically with knowledge managing capabilities' of individual employees as well as organization.

The study presents NGOs some suggestions for managing their knowledge resources effectively. A KM-model is proposed as a framework for NGOs. This model suggests that in order to manage knowledge resources effectively, a coordinated effort of enhancing knowledge capabilities of individuals and organization is required. More specifically, the model suggests that the NGOs' efforts to enhance knowledge capabilities of their employees will improve knowledge processing capabilities and ultimately will result better performance.

The NGOs investment in human resource KM capabilities will improve their methods, processes, tools and techniques and would cause better organizational performance. Future research should 
focus on examining the model empirically, in facilitating the development and implementation of KM programs within NGOs.

\section{References}

Alavi, M., \& Leidner, D. E. (2001). Review: KM and KM systems: Conceptual foundations and research issues. MIS Quarterly, 25(1), 107-136.

Barth, S. (2004). Self-Organization: Taking a Personal Approach to KM. Knowledge board http://www. knowledgeboard.com/download/3285/pkm-chapter-stevebarth.pdf, accessed on 13 January, 2010.

Bartol, K. M., \& Srivastava, A. (2002). Encouraging knowledge sharing: The role of organizational rewards systems. Journal of Leadership and Organization Studies, 9(1), 64-76.

Bhatt, G.D. (2001). Management Strategies for individual knowledge and organizational knowledge. Journal of KM, 6(1), 31-39.

Brown, J., \& Duguid, P. (1998). Organizing knowledge, California Management Review, 40, 90-112.

Buckman, R. H. (2005). The world is getting flatter: three future trends for KM. KM Review, 8 (5), 45 .

Caldwell, F. (2004). The future of KM. KM World, 13 (9), 1.

Currie, G., \& Kerrin, M. (2003). Human resource management and KM: enhancing knowledge sharing in a pharmaceutical company. International Journal of Human Resource Management, 14(6), 1027-1045.

Dalkir, K. (2005). KM in theory and practice. Oxford, UK: Elsevier Butterworth-Heinemann, pp. 3, 253, 279.

Davenport, T. H., De Long, D. W., \& Beers, M. C. (1998). Successful KM projects. Sloan Management Review, 39(2), 43-57.

Davenport, T. H., \& Prusak, L. (1998). Working Knowledge. Boston: Harvard Business School Press.

Earl, M. (2001). KM Strategies: Toward a Taxonomy, Journal of Management Information Systems, $18(1), 221-233$.

Egbu, C.O. (1999). The role of KM and innovation in improving construction competitiveness, Building Technology and Management Journal 25(1), 1-10.

Fitz-enz, J., \& Chatzkel, J. (2002) "Knowledge Capital: How Knowledge-Based Enterprises Really Get Built.” Drake Business Review, 1(1), 11-19.

Giuseppe, Pirró., Carlo, Mastroianni., \& Domenico Talia (2010). Future Generation Computer Systems, 26, 38-49.

Grant, G., \& N. Shahsavarani (2006). A Socio-Technical View of Knowledge Creation and Storage in Organizations. Proceedings, 4th International Management Conference, Tehran, December 20-21.

Grant, R.M. (1996). Toward a knowledge based theory of the firm. Strategic Management Journal $17,109-122$.

Gray, P.H., \& D.B. Meister. (2006). Knowledge sourcing methods. Information \& Management 43 (2), 142-156.

Grover, V., \& T.H. Davenport., (2001). General perspectives on KM: fostering a research agenda. Journal of Management Information Systems 18 (1), 5-21.

Hedlund, G. (1994). A model of KM, the N-Form Corporation. Strategic Management Journal, 15, 73-90.

Horowitz, F.M., Heng, C.T., \& Quazi, H.A. (2003). 'Finders, keepers? Attracting, motivating and retaining knowledge workers.' Human Resource Management Journal, 13(4), 23-44.

Hunter, L., Beaumont, P. \& Lee, M. (2002). KM practice in Scottish law firms. Human Resource Management Journal, 12(2), 4-21.

Hwang, A. (2003). Training strategies in the management of knowledge. Journal of KM, 7(3), 92104.

Ikhsan, S., \& Rowland, F. (2004). KM in a public organization: a study on the relationship between organizational elements and the performance of knowledge transfer. Journal of KM, 8(2), 96-111. 
Johannessen, J. A., Olaisen, J., \& Olsen, B. (2001). Mismanagement of tacit knowledge: The importance of tacit knowledge, the danger of information technology and what to do about it. International Journal of Information Management, 21(1), 3-20.

Kimble, C., \& Bourdon, I. (2008). Some success factors for the communal management of knowledge. International Journal of Information Management, 28(6), 461-467.

Kinney, T. (1998). KM, intellectual capital and adult learning, Adult Learning, 10 (2), 2-5.

Kwan, M.M., \& Balasubramanian, P. (2003) Knowledge Scope: managing knowledge in context, Decision Support Systems 35 (4), 467-486.

Kerschberg, L. (2001). KM in heterogeneous data warehouse environments, in: Proc. of DaWaK, Springer.

Laurie, J. (1997). Harnessing the power of intellectual capital. Training and Development, 27 (4), 66-77.

Lengnick-Hall, M., \& Lengnick-Hall, C. (2003). Human Resource Management in the Knowledge Economy. Berrett-Koehler, San Francisco.

Lubit, R. (2001). Tacit Knowledge and KM: The Keys to Sustainable Competitive Advantage. Organizational dynamics, 29 (4), 164-178.

Mclnerney, C. (2002). Hot topics: KM--a practice still defining itself. Bulletin of the American Society for Information Science and Technology, 28 (3), 14.

Mostashari, A. (2005). An Introduction to Non Governmental Organizations Management. [Online] Available from: http://web.mit.edu/isg/NGOManagement.pdf [Accessed 20 March 2010]

Nah, F., K. Siau., \& Y. Tian. (2005). KM mechanisms of financial service sites, Communication of the ACM, 48 (6), 117-123.

Nonaka, I. (1994). A dynamic theory of organizational knowledge creation. Organization Science, 5(1), 14-37.

Rumizen, M.C. (2002). Knowledge Management. Pearson, Madison, WI.

Saint-Onge, H. (2001). Strategic Capabilities: Shaping KM within the Knowledge-Driven Enterprise (On-line) http://www.knowinc.com/saintonge/ library/strategic.htm. Accessed 17/02/2011.

Scarbrough, H. (2003). KM, HRM and the innovation process. International Journal of Manpower, 24 (5), 501-516.

Schuler, R.S., \& Jackson, S. E., (2003). Linking Competitive Strategies with Human Resource Management Practices. in S. Little, P. Ouintas and T. Ray (eds.) Managing Knowledge: An Essential Reader, London: The Open University in association with Sage Publications.

Schultze, U. (1998). Investigating the Contradictions in KM, in: IFIP Conference on Information Systems, Helsinki, pp. 155-174.

Sher, P.J., \& V.C. Lee., (2004). Information technology as a facilitator for enhancing dynamic capabilities through KM. Information \& Management, 41 (8), 933-945.

Smith, K., Collins, C., \& Clark, K. (2005). Existing knowledge, knowledge creation capability, and the rate of new product introduction in hightechnology firms. Academy of Management Journal, 48(2) 346-357.

Stewart, T. A., (1994). Your companies' most valuable asset: intellectual capital. Fortune, October, pp. 68-94.

Swarts, J., \& Kinnie, N., (2003). Sharing knowledge in knowledge-intensive firms. Human Resource Management Journal, 13(2), 60-75.

Switzer, C. (2008). Time for change: empowering organisations to succeed in the knowledge economy. Journal of Knowledge Management, 12 (2), 18-28.

Vasconcelos, J., Seixas, P., Chris, K., \& Lemos, P. (2005). KM in Non-Governmental Organizations: A Partnership for the Future, Proceedings of the 7th International Conference on Enterprise Information Systems (ICEIS 2005), Miami, USA, May 24-28, ISBN: 972-8865-19-8.

Zaharias, P., Samiotis, K. \& Poulymenakou, A. (2001). Learning in knowledge-incentive organizations: methods and tools for enabling organizational learning processes. 7 th international 
886

conference on concurrent enterprising, Bremen. Available from: www.knowledgeboard.com/library/organizational_learing. pdf, accessed 18 February, 2010.

Zárraga, C., \& Bonache, J. (2003). Assessing the team environment for knowledge sharing: an empirical analysis. International Journal of Human Resource Management, 17(7), 1227-1245. 